\title{
Small is beautiful? Explaining resident satisfaction in Swedish nursing home care
}

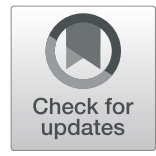

\author{
Douglas Spangler $^{1^{*}} \mathbb{D}$, Paula Blomqvist ${ }^{2}$, Ylva Lindberg ${ }^{3}$ and Ulrika Winblad ${ }^{4}$
}

\begin{abstract}
Background: Resident satisfaction is an important aspect of nursing home quality. Despite this, few studies have systematically investigated what aspects of nursing home care are most strongly associated with satisfaction. In Sweden, a large number of processual and structural measures are collected to describe the quality of nursing home care, though the impact of these measures on outcomes including resident satisfaction is poorly understood.

Methods: A cross-sectional analysis of data collected in two nationally representative surveys of Swedish eldercare quality using multi-level models to account for geographic differences.

Results: Of the factors examined, nursing home size was found to be the most important predictor of resident satisfaction, followed by the amount of exercise and activities offered by the nursing home. Measures of individualized care processes, ownership status, staffing ratios, and staff education levels were also weakly associated with resident satisfaction. Contrary to previous research, we found no clear differences between processual and structural variables in terms of their association with resident satisfaction.

Conclusions: The results suggest that of the investigated aspects of nursing home care, the size of the nursing home and the amount activities offered to residents were the strongest predictors of satisfaction. Investigation of the mechanisms behind the higher levels of satisfaction found at smaller nursing homes may be a fruitful avenue for further research.
\end{abstract}

Keywords: Nursing home, Eldercare, Quality, Satisfaction, Sweden

\section{Background}

The increasingly elderly population in many western countries has created an increased demand for high quality medical and social care services. This includes nursing home $(\mathrm{NH})$ care, referring to facilities providing 24-h functional support and care for persons who require assistance with activities of daily living and who often have complex healthcare needs [1]. Achieving quality in $\mathrm{NH}$ care is complicated by the fact that care quality is multifaceted, difficult to define and measure, and may be perceived differently by different stakeholders [2]. Regulatory agencies thus often struggle to identify factors most important in achieving high-quality $\mathrm{NH}$ care [3].

A particular challenge in regulating quality in $\mathrm{NH}$ care is that it is in many regards a 'soft' service in which the

\footnotetext{
* Correspondence: douglas.spangler@pubcare.uu.se

1 Department of Public Health and Caring Sciences, Uppsala University, Box

564, 75122 Uppsala, Sweden

Full list of author information is available at the end of the article
}

individual experiences of the $\mathrm{NH}$ residents is an important dimension of quality. While many aspects of quality (e.g, clinical quality and cost effectiveness) must be considered in order to achieve a well-rounded assessment of the care provided at a given nursing home, some scholars have argued that resident satisfaction may be the most appropriate assessment of quality in $\mathrm{NH}$ care $[4,5]$. In health care, investigations of patient satisfaction are abundant $[6,7]$, while studies measuring $\mathrm{NH}$ resident satisfaction are less common. This may be due to the suggestion that elderly patients with cognitive weaknesses have difficulty reliably answering surveys [5], though studies have shown that patients in cognitive decline are capable of answering surveys, particularly if they are designed with their needs in mind [8-11].

Given that the satisfaction of residents is an important dimension of quality in $\mathrm{NH}$ care, the question becomes how this is achieved. That is to say, what factors are most important to focus on when seeking to improve

(c) The Author(s). 2019 Open Access This article is distributed under the terms of the Creative Commons Attribution 4.0 International License (http://creativecommons.org/licenses/by/4.0/), which permits unrestricted use, distribution, and 
the satisfaction of $\mathrm{NH}$ residents? The most commonly used analytical framework for understanding how quality is generated in health and social care is Donabedian's structure - process - outcome model [12,13]. A central distinction in Donabedian's model is that between structural and processual quality factors, which are seen as potential explanatory factors behind quality outcomes. Structural factors refer to the physical attributes of the setting in which care is provided, including the number and qualifications of staff, equipment, and physical facilities [13]. Processual factors denote the manner in which the care services are delivered, e.g. whether care routines follow set guidelines, and the extent to which residents are involved in decisions about their care. Quality outcomes can be measured in many ways, both objectively in the form of health status or subjectively in the form of patient/resident satisfaction [12]. A central unresolved question posed in Donabedian's work is whether structural or processual measures are most important for generating outcome quality, and precisely how these factors interact to produce the desired outcomes.

The literature on medical quality in $\mathrm{NH}$ care in terms of, for instance, mortality and adverse event rates, has investigated numerous explanatory factors including staffing, ownership, care routines, and the size of facilities [14-17]. Such studies are particularly abundant in the United States, where collection of the Minimum Data Set provides a robust basis for performing broad studies of clinical outcomes. There are considerably fewer investigations of the determinants of resident satisfaction. Previous studies have investigated structural factors including staff satisfaction [18], and job commitment [19], with both studies finding positive associations with resident satisfaction. A broader study of the influence of organizational factors found that $\mathrm{NH}$ ownership, staffing levels, and the provision of family councils were important predictors of $\mathrm{NH}$ resident satisfaction [20]. Others have investigated specific interventions related to processual quality factors such as improved meal time routines [21], "person-centered care" initiatives [22], and social activity programs such as gardening [23]. While generally finding positive effects on resident satisfaction, these interventional studies are narrow, and differ in terms of setting and methodology, making them difficult to compare. Taken together, the prior literature on what factors are associated with resident satisfaction in $\mathrm{NHs}$ is largely limited to evaluations of specific interventions, and there are few studies investigating the relative influence of structural and processual factors, particularly in the European context.

In Sweden, several public investigations have pointed to quality deficiencies, and a lack of systematic knowledge about factors leading to improved quality $[24,25]$. The issue of $\mathrm{NH}$ care quality has increased in significance in Swedish public debate as reforms have led to an increasing number of homes contracted out by local governments (municipalities) to private, often for-profit firms. In 2017, one study found that about one fifth of the Swedish NHs were run by for-profit providers [26]. This study, as well as another recent investigation of Danish NHs, found that overall, privately operated homes outperformed public and non-profit homes in terms of process measures, while underperforming in terms of structural measures [26, 27]. Neither of these studies investigated resident satisfaction however.

In Sweden, there is good availability of data on various aspects of $\mathrm{NH}$ care due to comprehensive data collection efforts by the Swedish National Board of Health and Welfare (NBHW). Annual surveys measuring satisfaction are sent by the NBHW to all NH residents, and surveys assessing processual and structural measures of quality are sent to every NH in Sweden. So far however, the use of these data for research has been limited. One exception is a study by Kajonius and Kazemi [28] which investigated differences in satisfaction among $\mathrm{NH}$ residents at the municipal level, finding that processual quality factors such as respect and access to information appeared to be more important for residents than structural factors such as staffing and budget.

In this study, we aim to evaluate which structural and processual measures of quality have the strongest associations with overall $\mathrm{NH}$ resident satisfaction. In doing so, we hope to provide policymakers and researchers with a broader picture of the determinants of resident satisfaction as $\mathrm{NHs}$ than has previously been available.

\section{Methods \\ Setting}

In Sweden, all citizens have access to publicly funded $\mathrm{NH}$ services at heavily subsidized rates. The eldercare system in Sweden is decentralized, with responsibility for service provision resting with the nation's $290 \mathrm{mu}$ nicipalities. Municipalities are obliged to offer NH care to those determined to have a need for such care based on national criteria. The municipality may provide services themselves, or contract out service provision to private entities [29]. In 2016, there were in total 88,886 individuals [30] living in ca. $2300 \mathrm{NHs}$ in Sweden [31], with $20.5 \%$ of residents living in NHs operated by private providers [30]. While marketization reforms have led to an increase in the proportion of privately managed NHs, they remain publicly funded [32]. All NHs, both public and private, are subjected to the same national quality reporting requirements, user safety regulations, and auditing measures [33]. This study includes all NHs in Sweden providing care to individuals over 
65 years of age in 2016, excluding facilities offering only short-term care.

\section{Data collection}

Two nationally representative surveys conducted in 2016, both developed and administered by the NBHW, serve as the primary sources of data. The first survey is a user satisfaction survey (Brukarundersökningen, or user survey) distributed yearly to all individuals over 65 years of age receiving elder care services including $\mathrm{NH}$ care. This survey consists of 27 separate items to be rated on a five-point Likert scale, relating to their satisfaction with a variety of aspects of elder care services, as well as their health status. Among those living in $\mathrm{NHs}$ the survey had a response rate of $56 \%$ in 2016 , resulting in a total of 40,371 responses [34].

The second data source is a survey sent directly to all NHs in Sweden by the NBHW, which assesses a number of processual and structural measures of quality. This survey (Enhetsundersökningen, or unit survey) is completed by administrative staff at each $\mathrm{NH}$, and had a response rate of $93 \%$ in 2016, resulting in 2153 responses [35]. In addition to quality measures, the unit survey provides data on the type of services provided by the $\mathrm{NH}$ (general, dementia and/or assisted living), the number of residents in each home, and whether the NH is operated by a public or private entity. While the NBHW has a long experience of developing and administering surveys, and assessments of loss-to follow-up in the user survey have been performed [36] the psychometric properties of these surveys have not been published in the publicly available literature .

Observations in the two NBHW survey datasets for 2016 were matched based on the NH name and municipality. This involved both an automated matching process, and a subsequent manual review of unmatched records. Municipality-level variables were extracted from the national municipality and county council database Kolada [37] and merged into the dataset.

\section{Variables}

Variables for analysis were aggregated from the two surveys based on their conceptual meaning and the results of an exploratory factor analysis which may be found in Additional file 1, p 1-7. The extracted variables are detailed below, and a summary of the categorization is available as Additional file 2.

\section{Dependent variable}

Upon exploratory factor analysis, it was found that questions in the user survey were highly correlated (Cronbach's Alpha $=0.92$ ), and was a poor candidate for approaches based on extraction of distinct latent variables. As such, we chose to extract a single composite measure of satisfaction from the user survey for use as the dependent variable, consisting of questions 5-19, 21-25, and 27. To generate a composite measure for use as the dependent variable, the percent of residents at a nursing home responding positively to a given survey question was normalized by subtracting the average percentage of patients responding positively to that question in the population, and dividing by the standard deviation of the population, resulting in a standardized z-score. Z-scores were then averaged across all included survey items to result in a composite score with equal weights for each question.

\section{Independent variables}

The NBHW divided the unit survey into 12 conceptual categories. A factor analysis showed that the individual questions generally loaded well onto the categories proposed by the NBHW and it was therefore chosen, with a few exceptions, to retain this categorization as the basis for the independent variables used in the analysis. Based on the Donabedian model, the independent variables were divided into "structural" and "processual" variables.

\section{Processual variables}

The first seven variables related to different processual factors, such as meal-related routines or physical or social activities.

Questions 1 and 1a in the unit survey related to the ability of residents to participate in "resident councils" where residents regularly meet to voice concerns in the $\mathrm{NH}$. Issues raised during resident councils may for instance include the planning of common activities or menus for the coming weeks. These were aggregated and reported as the variable Participation in resident councils.

Questions 2 and 3 in the unit survey concerned the existence of-, and the residents participation in, the creation of "action plans" concerning the care needs and wishes of the resident. These action plans contain information about how various care activities are to be carried out and should be updated every 6 months. The questions were combined into the variable Individualized action plans.

Questions 4 and 5 addressed the existence of mealrelated routines, and the documentation of meal preferences in the residents' action plans. Such meal routines are to be based on the Five Aspects Meal Model (FAMM) proposed by Gustafsson et al. [38], and should be updated every 24 months. The questions were combined into the variable Meal-related routines and plans.

Questions 6a-c in the survey related to the existence of formal routines for handling resident safety issues such as threats, violence, and addiction. While the NBHW grouped question 7 (routines for cooperation 
with relatives) into this category, it did not load well onto a common factor and is conceptually quite distinct, and was therefore excluded. The remaining questions were combined into the variable Patient safety routines.

Questions 8 and 8a-b in the unit survey related to facilities for-, and availability of, exercise and social activities. We excluded question 8 (whether the $\mathrm{NH}$ residents have access to facilities for physical activity), which had a weak-to-moderate factor loading, so as to interpret this variable as a purely process-related measure. The remaining questions were combined into the variable Availability of exercise and social activity.

Questions 9 and 10 related to the existence of routines for planning care in cooperation with other healthcare providers, and whether resident's involvement was documented. Similarly, questions 11 and 12 related to routines for medication reviews and whether resident participation is documented in the medical record. We reported these as the variables Care coordination routines and Medication review routines, respectively.

\section{Structural variables}

The structural variables included indicators of staffing, ownership and size. Three factors relating to staffing from the unit survey, including the ratio of nurses per resident (questions 13 and 14), non-nurse staff per resident (questions 15 and 16), and the portion of staff with an "adequate education" for their position (questions 17 $\& 18)$ were identified. These are reported as the variables Nurses per resident, Staff per resident, and Staff with adequate education respectively, and weekday and weekend staffing levels were weighted at a 5:2 ratio to represent average daily staffing levels. While staffing ratios are fairly straightforward to calculate, the definition of what constitutes an "adequate education" is more complex. Adequacy is determined by the amount of healthcarerelated training completed by non-nurse staff based on a point scale established by the NBHW [39].

The number of beds available at each $\mathrm{NH}$ was reported as Size of nursing home. The NH's ownership status, i.e. whether it was run by a private or a public provider, was reported as the variable Private ownership.

\section{Controls}

Several variables were included in the analysis to control for population health differences between the NHs included in this study. Self-rated health has been found to be an excellent predictor of clinical outcomes [40, 41], and we used questions $1-3$ and 20 in the user satisfaction survey, which asked about the residents' physical and mental well-being, to control for health status. The type of facilities (general, dementia and/or assisted living) available at the $\mathrm{NH}$ was also controlled for.
It was further deemed necessary to control for demographic factors for which data was only available at the municipal level. This refers to different demographic, economical, and political conditions which may vary significantly between the 290 municipalities. A set of controls were adapted from previous studies $[26,42,43]$ including per capita income levels, population density, age profiles, political control, and expenditures, the details of which may be found in Table 1. Data at the municipality level was collected from the Kolada database [37].

\section{Statistical analysis}

As the large number of quality measures made available by the NBHW was unsuited to direct inclusion in a regression-modelling framework, an initial exploratory factor analysis was performed to reduce the dimensionality of the dataset as described above. Data from the user satisfaction survey and the unit survey were aggregated at the $\mathrm{NH}$ level. We sought to minimize bias in the estimation of the effects of the investigated quality measures by drawing upon the approach to causal modelling first described by Pearl [44], using the assumptions of causal directionality described by the Donabedian model of healthcare quality $[12,13]$. The Donabedian model asserts that a causal relationship exists between structural and processual aspects of healthcare quality, and we assumed that the satisfaction of $\mathrm{NH}$ residents would be confounded by their health status. To control for confounding due to these causal relationships, the effects of processual measures of quality were modeled controlling for resident health and structural measures of quality. We present coefficient estimates for structural measures including controls for other measures of structural quality, though the direction of causality within the selected set of structural measures is in many cases unclear. In addition to these full models, we present additional nested models estimating bivariate associations, and models controlling only for resident health. In this framework, variations in the regression coefficients between the full and nested models allowed for the interpretation of the impact of health status and structural factors on the effect of the quality measures.

The aggregated variables were first analyzed in a classical ordinary least squares regression framework using the Huber-White sandwich estimator to account for heteroscedasticity and clustering as implemented in the rms $\mathrm{R}$ package [45]. Hierarchal models including municipality-level controls with random intercepts for municipalities were implemented using a "Partial pooling" approach to account for clustering and confounding due to municipal-level factors [46], as implemented in the lme4 $\mathrm{R}$ package [47]. Confidence 
Table 1 Descriptive statistics of aggregate variables

\begin{tabular}{|c|c|c|c|c|c|}
\hline & Mean & SD & Median & IQR & Missing \\
\hline \multicolumn{6}{|l|}{ Dependent variable } \\
\hline Aggregate resident satisfaction & $0.01^{*}$ & $1.00^{*}$ & 0.05 & 1.34 & 4 \\
\hline \multicolumn{6}{|l|}{ Processual variables } \\
\hline Participation in resident councils & $0.00^{*}$ & $1.00^{*}$ & 0.48 & 1.63 & 0 \\
\hline Individualized action plans & $0.00^{*}$ & $1.00^{*}$ & 0.48 & 1.00 & 0 \\
\hline Meal-related routines and plans & $0.00^{*}$ & $1.00^{*}$ & -0.17 & 1.60 & 53 \\
\hline Patient safety routines & $0.00^{*}$ & $1.00^{*}$ & -0.35 & 1.98 & 0 \\
\hline Care coordination routines & $0.00^{*}$ & $1.00^{*}$ & -0.05 & 2.07 & 0 \\
\hline Medication review routines & $0.00^{*}$ & $1.00^{*}$ & 0.09 & 2.18 & 0 \\
\hline Availability of exercise and activities & $0.00^{*}$ & $1.00^{*}$ & 0.08 & 1.82 & 0 \\
\hline \multicolumn{6}{|l|}{ Structural variables } \\
\hline Private ownership of nursing home & 0.19 & 0.39 & 0.00 & 0.00 & 1 \\
\hline Size of nursing home & 43.57 & 22.70 & 39.00 & 25.00 & 6 \\
\hline Nurses per resident & 0.03 & 0.01 & 0.03 & 0.02 & 62 \\
\hline Staff per resident & 0.29 & 0.06 & 0.28 & 0.06 & 41 \\
\hline Staff with adequate education & 83.71 & 14.12 & 86.86 & 18.54 & 40 \\
\hline Has general care facilities & 0.79 & 0.41 & 1.00 & 0.00 & 0 \\
\hline Has dementia care facilities & 0.59 & 0.49 & 1.00 & 1.00 & 0 \\
\hline Has assisted living facilities & 0.05 & 0.23 & 0.00 & 0.00 & 0 \\
\hline \multicolumn{6}{|l|}{ Resident Health Controls } \\
\hline Aggregate self-rated health & $0.01^{*}$ & $1.00^{*}$ & -0.04 & 1.31 & 12 \\
\hline \multicolumn{6}{|c|}{ Municipal controls (Weighted by \# of nursing homes in Municipality) } \\
\hline Population 65+ in Nursing Home (\%) & 4.21 & 0.88 & 4.21 & 0.99 & 19 \\
\hline Population $65+(\%)$ & 21.22 & 4.19 & 21.20 & 6.33 & 0 \\
\hline Population per square kilometer & 472.4 & 1164.7 & 60.6 & 116 & 0 \\
\hline Average annual cost per resident (SEK) & 838,285 & 161,812 & 822,686 & 117,267 & 19 \\
\hline Average age of residents in nursing homes & 83.49 & 1.82 & 83.60 & 2.30 & 0 \\
\hline Political control (left $=-1$, mixed $=0$, right $=1)$ & -0.12 & 0.80 & 0.00 & 2.00 & 0 \\
\hline Average annual per capita taxable income (SEK) & 188,232 & 24,921 & 183,269 & 23,691 & 0 \\
\hline
\end{tabular}

*These variables are mean centered and normalized. The reader may draw conclusions regarding the distribution of the normalized variables by examining the median to determine skew, and IQR to assess for kurtosis (a standard normal distribution has an IQR of 1.35)

intervals were generated using basic parametric bootstrap resampling.

In this analysis, we report our results in terms of standardized regression coefficients. While this allows for direct comparison of the importance of each independent variable in predicting resident satisfaction, it makes interpretation in terms of absolute effects cumbersome. Given the low rates of missing data at the unit level, multiple imputation was not deemed to be necessary, and cases with missing values were deleted list-wise in the relevant models. All statistical analyses were performed using $\mathrm{R}$ version 3.5.0, and a reproducible accounting of our reported findings is included as Additional file 1. A number of sensitivity analyses investigating the impact of various model specifications, potential biases due to loss to followup, and assumptions made in the main analysis are also included in Additional file 1. Source code and the data necessary to reproduce these findings are available on Mendeley Data [48].

\section{Results}

Data from both surveys (the user survey and the unit survey) were aggregated at the $\mathrm{NH}$ level, resulting in 1921 records in the user survey, and 2189 records in the unit survey. 1711 records could be automatically linked based on municipality and $\mathrm{NH}$ names, and an additional 87 records could be matched through manual review, resulting in a dataset containing $1798 \mathrm{NHs}$. An analysis of non-matched records may be found in 
Additional file 1. p 7-8. An analysis of the association between survey response rates and the investigated variables was performed. We found a positive association between response rates and resident satisfaction, as well as a negative association between response rates and nursing home size, and an effect indicating that private nursing homes had higher response rates (See dropout analysis in Additional file 1, p 8). Generally, residents of NHs were quite satisfied; in the 2016 survey, 83\% answered that they overall were fairly or very satisfied with the care they received.

\section{Descriptive data}

Descriptive statistics were generated for each of the variables included in the analysis, and are presented in Table 1. We found that the average $\mathrm{NH}$ in Sweden has space for 43 residents, a resident to staff ratio of roughly 3.5:1, a resident to nurse ratio of $30: 1$, and that $83 \%$ of nonnurse staff had an adequate level of education as defined by the NBHW criteria. 19\% of included NHs were operated by private providers. $80 \%$ of $\mathrm{NHs}$ offered general care services, while $60 \%$ offered dementia care services, and only $5 \%$ had assisted living facilities - These sum up to over $100 \%$ as a single $\mathrm{NH}$ can offer more than one type of service.

With regard to municipality level statistics, we see that about $21 \%$ of Swedes are over the age of $65,4 \%$ of whom live in NHs, where the average age of residents is 83 . The average annual per-resident cost for the municipality is 838 thousand SEK (around 80 thousand EUR), while average per capita taxable income is 188 thousand SEK (Table 1).

\section{Regression analysis}

Figure 1 presents the summarized results of each of the models developed to characterize the independent variables created from the unit survey. 1a presents the results using a classical OLS regression framework, while $1 \mathrm{~b}$ presents the results of hierarchal mixed-effects models controlling for municipal level effects.

In terms of overall predictive value, an OLS model including all covariates achieved an adjusted $\mathrm{r}^{2}$ of 0.182 , while the conditional $r^{2}$ value [49] of the multi-level model containing all predictor variables was 0.254 . In the multi-level framework, we found that variation between municipalities accounted for $10 \%$ of the total variation found between NHs. A total of 12 processual and structural variables were extracted from the unit survey for analysis as independent variables. Upon analyzing the results, variable groupings were identified post hoc based on similarities with regard to effect sizes and conceptual meanings, which are used to simplify the discussion of our findings, and are labelled on the right-hand side of Fig. 1.
The variables in the first group, labelled Individualized care, are all related to the individual care process. They include the variables Participation in resident councils, Individualized care plans, and Meal-related routines and plans. This group had an average effect size of 0.06 in our fully controlled models, and while 95\% confidence intervals in the main model consistently excluded zero after adjusting for municipality-level covariates. The significance of the variables in this group varied upon sensitivity analyses however (See Additional file 1, p 22-25).

The next group, labelled Safe care, includes the variables Patient safety routines, Care coordination routines, and Medication review routines. They are all related to the existence of formal guidelines dealing with various aspects of care. As seen in Fig. 1, none of these variables displayed significant correlations to resident satisfaction.

The final group in the processual category consists of only one variable, Availability of exercise and social activity. This variable, labelled Activity, displayed the highest degree of correlation with overall resident satisfaction among the process variables, with an effect size of 0.11 in our fully controlled model, and was robust across a range of sensitivity analyses.

Turning to the structural variables, another three variable groups were identified. We identified no significant effects in the OLS model with regard to ownership status. Upon controlling for municipality-level variables, a significant positive correlation with a magnitude of 0.06 in the fully controlled model was found, though the significance of the association was sensitive to variations in model specifications.

The Size of the NH was by a significant margin the most important predictor of resident satisfaction in this analysis, with the negative coefficient suggesting that smaller NHs are associated with more satisfied residents. A small decrease in the effect of this variable could be noticed upon controlling for municipality level effects, suggesting that larger $\mathrm{NHs}$ may be more common in municipalities where residents are on average, less satisfied with their $\mathrm{NH}$ care. The effect of size was robust in our sensitivity analyses.

The third group of structural variables included Nurses per resident, Staff per resident and Staff with adequate education, and was labelled Staffing. The group as a whole had an average effect size of 0.05 among the fully controlled models. With the exception of nurse staffing ratios, 95\% confidence intervals consistently excluded zero in the main models, but the significance of the effect was sensitive to varying model specifications.

Taken together, the results of the analysis presented in Fig. 1 show that the structural measure Size of the $\mathrm{NH}$ was the most important predictor of resident satisfaction, followed by the processual Availability of exercise 


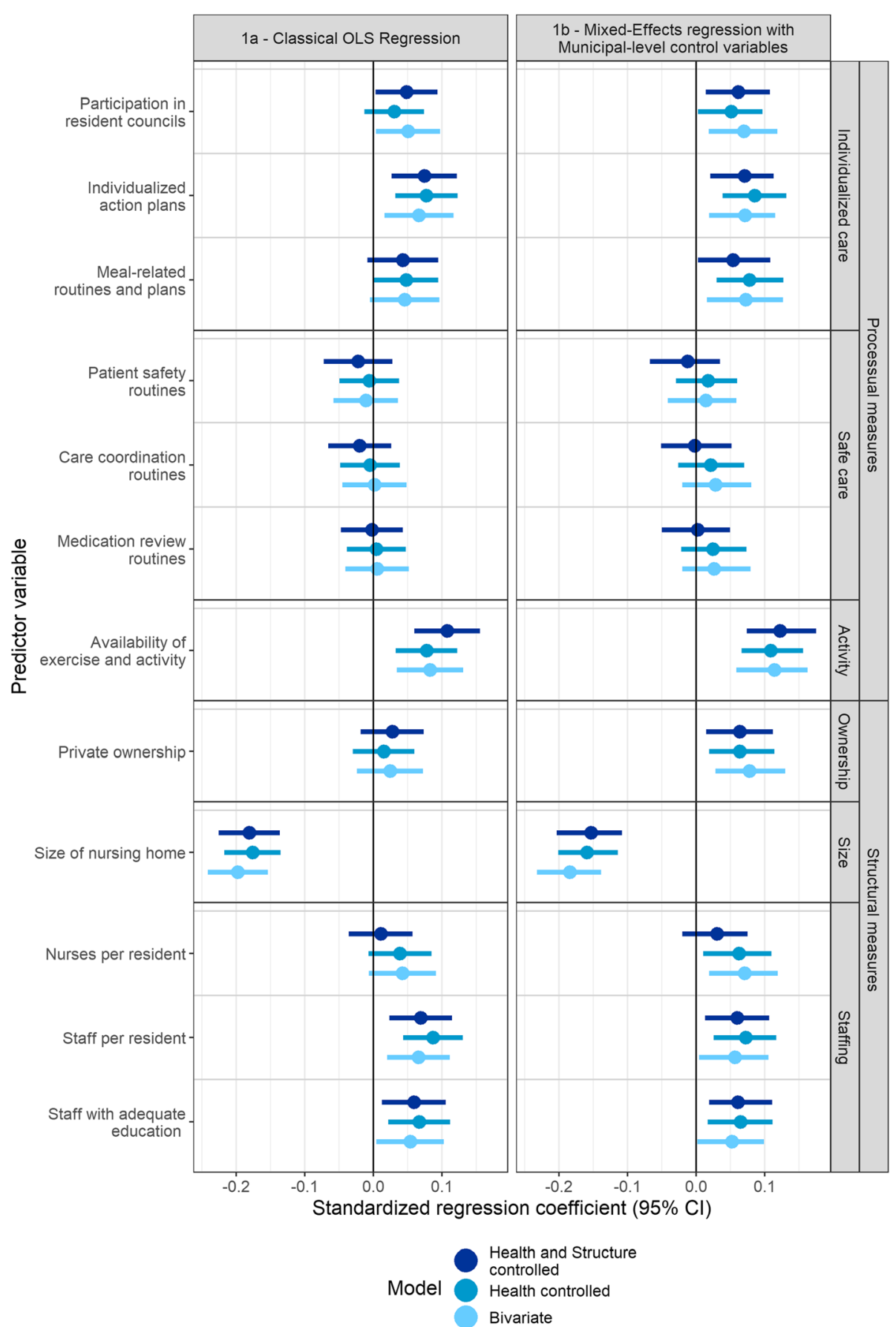

Fig. 1 Standardized regression coefficients of predictors for composite resident satisfaction. This figure presents standardized regression coefficients for each of the analyzed independent variables. Coefficients are presented for models including only the relevant independent variable (bivariate), with controls for only the health status of the patient (Health controlled), and with controls for both health status and the structural measures (Health and Structure controlled)

and social activity variable. The effects of the processual Individualized care variables and the structural Staffing variables were similar in magnitude, as was the effect of Private ownership, upon controlling for municipality- level effects. These effects were also sensitive to alternate model specifications. The processual Safe care variables were not found to have any significant association with resident satisfaction. 
Finally, a comment on the significant effects found among our control variables is in order. In our fully controlled model, self-rated health was found to have a strong positive correlation with satisfaction (standardized regression coefficient of 0.34) suggesting that healthier residents reported considerably higher levels of satisfaction. Among the municipality level controls, average $\mathrm{NH}$ resident age had a positive correlation with satisfaction, and average per capita taxable income had a negative correlation with satisfaction. Interestingly, no significant relationship between the amount spent per resident and satisfaction was identified. Full model summaries, along with a table reporting the data upon which Fig. 1 is based may be found in Additional file 1, p 12-15.

\section{Discussion}

In this study, we investigated a total of 12 variables representing different aspects of care quality reported in the NBHW unit survey. Of these, seven were considered to represent process-related quality, and five to represent structural quality. Our main findings were that the Size of a $\mathrm{NH}$ (a structural measure) had the greatest impact on resident satisfaction, followed by the processual measure Availability of exercise and social activities. The processual variables concerning Individualized care and the structural Staffing and Private ownership all had similar, weakly positive, effects on resident satisfaction. The processual Safe care variables had no significant effect on resident satisfaction. We found no clear differences in terms of effect sizes between processual and structural variables. Below, we discuss these findings in order of the effect size identified in our results.

The fact that $\mathrm{NH}$ size was the best predictor of resident satisfaction suggests that smaller NHs in Sweden had more satisfied residents than their larger counterparts. A recent literature review surveying studies examining the impact of $\mathrm{NH}$ size on quality outcomes showed size to be an important predictor of quality, with smaller homes generally having better quality outcomes [15]. None of the 30 studies investigated the relationship between size and resident satisfaction, though five investigated similar composite "Quality of Life" measures. There are however some indications that larger nursing homes may be associated with better clinical outcomes such as lower hospitalization risks [50] and lower rates of antipsychotic medication use [51]. NH quality is a multi-faceted concept, and it is not necessarily the case that the determinants of quality will affect all aspects of quality in the same way. As such, while this study does add to the evidence that smaller NHs are associated with the type of "soft" quality which resident satisfaction may be said to represent, the results should not be interpreted as saying anything regarding "harder" measures including clinical outcomes, the determinants of which may be quite different.

While size may be an important predictor of satisfaction in and of itself, it is also likely that there are causal mechanisms behind this association which mediate the effect of size. Previous research has for instance indicated that staff turnover may be lower [52] and staff continuity higher [53] at smaller NHs. The findings of this study thus emphasize the importance of identifying the more proximal mechanisms by which smaller NHs generate higher levels of satisfaction. The interpersonal aspects of nursing home care which these measures reflect are however difficult to measure, and investigating the mechanisms behind these softer dimensions of nursing home care may require a more qualitative approach.

The Availability of exercise and social activities was found to have the strongest association with resident satisfaction among the processual variables. Previous research has found that physical activity-related interventions can improve the subjective health status of $\mathrm{NH}$ residents [54], although other studies have found weaker or even negative effects [55]. Our results suggest that, overall, NHs which offer more frequent opportunities for exercise and social activity have higher levels of resident satisfaction. The effect of activity was not diminished by controlling for resident health or $\mathrm{NH}$ structure; rather, the effect increased slightly suggesting that the provision of such activities may be even more important at NHs with poorer structural preconditions, particularly with regard to facility size.

Three other variable groups had weaker effects with regards to resident satisfaction: Individualized care, Private ownership, and Staffing. The Individualized care variables included participation in resident councils, the use of individualized care plans and the use of meal routines. We identified no previous research regarding the impact of resident councils or the use of individualized care plans on satisfaction in the literature, though Lucas et al., [20] did identify a positive impact of similar "family councils". Our findings suggest that these quality improvement measures may indeed be associated with higher levels of resident satisfaction, although more directed studies are necessary to confirm this. There is some evidence that interventions to improve mealrelated processes are effective [56, 57], and our results are consistent with a positive impact of such improvements on resident satisfaction.

The structural measures related to staffing had effect sizes similar to those found among the processual individualized care measures. Staffing as a determinant of care quality has been well researched. In a review of 70 articles, Castle [58] found a preponderance of evidence suggesting that increased staffing levels are positively associated with several measures of $\mathrm{NH}$ care quality. More 
recent studies by Castle and Anderson [59], Hyer et al. [60], and Shin and Hyun [61] point to similar results. However, none of these studies investigated effects on resident satisfaction. We found that both non-nurse staffing ratios and education levels were associated with resident satisfaction in all models, while nurse to resident ratios were significant upon controlling for municipal-level factors, and effect sizes were reduced upon controlling for other structural factors. Our results are thus consistent with a positive relationship between staffing levels and $\mathrm{NH}$ care quality.

Regarding the effect of ownership, the main results suggest a higher level of resident satisfaction among privately operated $\mathrm{NHs}$ after controlling for municipal level covariates. That is to say, while there was no overall difference in absolute levels of satisfaction, a difference was identified upon taking into account that public and private $\mathrm{NHs}$ are not evenly distributed across Sweden, and that when the effects of this non-uniform distribution was accounted for (in effect comparing NHs within the same county), a difference could be identified. The somewhat counter-intuitive effect could, at least in part, be explained by the tendency of private care providers in Sweden to establish themselves in municipalities with higher income levels, where resident expectations may be higher. This supposition is supported by the finding that average per capita income had a significant negative association with resident satisfaction (see Additional file 1, p 17). The significance of ownership status was not robust in sensitivity analyses however, and as such constitutes quite weak evidence for the superiority of private over public nursing homes with regards to resident satisfaction.

While we found no association between measures of safe care and resident satisfaction, it stands to reason that the processes which these measures represent (e.g. the performance of regular medication reviews and the existence of care coordination plans) are not immediately visible to residents, and are thus less likely to influence satisfaction. Studies investigating the impact of these measures on clinical outcomes may well find that they do have an effect with regards to quality in that respect.

Taken together, the findings of this study indicate that $\mathrm{NH}$ residents are more satisfied in smaller NHs, and $\mathrm{NHs}$ with frequent opportunities for physical and social activity. Only weak effects were identified with regards to processual individualized care measures, private nursing home ownership, and staffing levels. Formal routines had no effect on the satisfaction of residents. Another contribution of the study is the comparison of the effect of structural and processual variables on satisfaction. In contrast to a previous study on Swedish $\mathrm{NH}$ care [28], this study did not lend support to any firm conclusions regarding the superiority of one type of quality measure over the other. Rather, it was demonstrated that both structural variables such as size, staffing and ownership, and processual variables including individualized care and activities play a role in determining resident satisfaction. The difference in results between the two studies could be explained by the fact that the processual and outcome variables in the Kajonius and Kazemi study were both drawn from the resident survey (which we found upon factor analysis to be highly inter-correlated), while the structural variables they were compared with were drawn from a separate statistical database lacking this overall correlation. It is thus likely that the differential effects identified by Kajonius and Kazemi are an artefact of how the authors chose to operationalize the processual and structural measures. Furthermore, in the study data was aggregated at the municipal level, thereby investigating only differences in resident satisfaction between municipalities, which we found to account for only $10 \%$ of the total variation in satisfaction between NHs.

\section{Strengths and limitations}

This study was a secondary analysis of two nationally representative surveys collected for quality improvement purposes. A strength of the study is thus that the results are likely to generalize well to other contexts similar to that of Sweden, and the wide scope of these surveys allowed us to investigate and compare a broad range of factors. A limitation of the study was that the validity and reliability of these surveys has not been established in the publicly available literature, although the NHBW has analyzed the impact of loss to follow-up in the user survey [62], and performs ongoing internal quality assurance of the surveys it conducts. Another risk involved in the secondary analysis of data is the proliferation of "researcher degrees of freedom" arising from the numerous decisions which must be made in transforming and analyzing such data [63]. To ameliorate these risks, we sought to define our analysis strategy a priori, and provide the resources necessary to fully reproduce our results [48]. Another limitation is that the aggregate data used in this study precludes the interpretation results in terms of individual-level effects, and readers must be careful to not commit the "ecological fallacy" of interpreting effects operative at the $\mathrm{NH}$ level as applying to individuals.

Among other simplifying statistical assumptions including those of additivity and linear effects, we assumed that each question in the survey was equally important to residents in generating the composite measure used as the dependent in our analysis. Weighting each question equally would seem to be a reasonable assumption 
to make in the absence evidence regarding resident preferences, and the main findings regarding nursing home size and availability of activities were robust to a range of sensitivity analyses and alternate survey question weights.

It was common for the satisfaction surveys to be completed with the assistance of third parties, which could potentially influence reported outcomes, and while the rate of missing data was too high to include this variable in the formal analysis, a sub group analysis of homes reporting data on this variable may be found in Additional file 1, p 21-22. Based on our findings, we do not expect this factor to be a threat to the validity of our results. We also analyzed the associations present within the user survey data between $\mathrm{NH}$ level response rates and the quality measurements reported in the study. We identified a positive correlation between response rates and satisfaction rates, as has been found in previous studies of this phenomenon $[64,65]$. We also identified effects suggesting that response rates were higher at smaller nursing homes, and at private nursing homes (See Additional file 1, p 8). Previous studies have suggested that low response rates are likely to result in an over-estimation of satisfaction [64]. As such, bias resulting from the systematic differences in response rates would likely be in the direction of underestimating the association of size and private ownership with satisfaction.

\section{Conclusions}

Of the quality factors investigated, $\mathrm{NH}$ size had the most prominent association with satisfaction, followed by the availability of exercise and social activities. Processual measures relating to individualized care, such as participation in resident councils and the formulation of individualized action plans had a weak association with resident satisfaction, as did other structural factors such as staffing ratios and staff education. The results also suggested that privately managed $\mathrm{NHs}$ had a slightly higher level of resident satisfaction, though the effect was similarly weak and appeared only after adjusting for municipality-level covariates. The results in this study suggest that both structural and processual quality factors matter in determining resident satisfaction, with $\mathrm{NH}$ size and the availability of exercise and activities having the greatest impact.

\section{Implications for policy and practice}

While the findings in this study suggest a direct link between offering more activities and a higher rate of satisfaction, more research is needed to determine why residents appear more satisfied at smaller homes. It may be that the proximal causes of satisfaction at smaller NHs could be replicated at their larger counterparts, for instance by improving staff continuity and turnover. If so, this could be a cost-effective alternative to building smaller nursing homes. Qualitative studies using methods such as interviews and participant observation may be most appropriate to investigate such effects in more depth. Another policy implication is that activities for residents should be a priority in $\mathrm{NH}$ care, and in cases where $\mathrm{NHs}$ care is contracted out, offering physical and social activities should be a requirement.

\section{Supplementary information}

Supplementary information accompanies this paper at https://doi.org/10. 1186/s12913-019-4694-9.

Additional file 1. Analysis_notebook. This document provides additional details regarding the factor analysis undertaken to reduce the dimensionality of the data prior to regression analysis, additional details regarding the main analysis, and a number of post-hoc analyses undertaken to evaluate the sensitivity of the findings, and investigate a number of interesting findings suitable for pursuit in further research.

Additional file 2. Survey_questions. This document details the specific questions from the two NHBW surveys constituting the aggregate variables included as independent variables in the regression analysis reported in this manuscript.

\section{Abbreviations}

FAMM: Five Aspects Meal Model; IQR: Inter-Quartile Range; NBHW: National Board of Health and Welfare; NH: Nursing Home; OLS: Ordinary Least Squares regression; SEK: Swedish Krona

\section{Acknowledgements}

We gratefully acknowledge financial support from the Swedish Research Council for Health Working Life and Welfare (FORTE). The authors wish to thank the National Board of Health and Welfare for providing the data used in the study, and the residents and nursing home administrators completing the surveys.

\section{Authors' contributions}

DS, UW and PB conceived of and designed the study. DS performed the analysis and drafted parts of the manuscript. YL performed data cleaning, record matching, and drafted parts of the manuscript. All authors provided substantial input and revisions, and approved the final manuscript.

\section{Funding}

The study was funded by the Swedish Research Council for Health, Working Life, and Welfare (FORTE), dnr 2014-05134. The funding body had no role in the design of the study or collection, analysis, and interpretation of data or in writing the manuscript. Open access funding provided by Uppsala University.

\section{Availability of data and materials}

All data used in this study are publicly available. The data and code use to generate these results are available on Mendeley data at: https://doi.org/10. 17632/y69zhgxym3.2

\section{Ethics approval and consent to participate}

This study was approved by the Uppsala regional ethics review board (dnr 2017-342). A waiver of informed consent was granted by the review board.

\section{Consent for publication}

Not applicable.

\section{Competing interests}

The authors declare that they have no competing interests. 


\section{Author details}

'Department of Public Health and Caring Sciences, Uppsala University, Box 564, 75122 Uppsala, Sweden. ${ }^{2}$ Department of Government, Uppsala University, Box 514, 75120 Uppsala, Sweden. ${ }^{3}$ Department of Public Health and Caring Sciences, Uppsala University, Box 564, 75122 Uppsala, Sweden. ${ }^{4}$ Department of Public Health and Caring Sciences, Uppsala University, Box 564, 75122 Uppsala, Sweden.

Received: 29 March 2019 Accepted: 30 October 2019 Published online: 25 November 2019

\section{References}

1. Sanford A, Orrell M, Tolson D, Abbatecola AM, Arai H, Bauer JM, et al. An International Definition for "Nursing Home." J Am Med Dir Assoc 2015;16(3): $181-184$.

2. Isaksson D, Blomqvist $P$, Winblad U. Privatization of social care delivery how can contracts be specified? Public Manag rev. 2017;27:1-20.

3. Colombo F, Murakami Y. Measuring quality in long-term care. In: OECD/ European Commission, editor. A Good Life in Old Age?: Monitoring and Improving Quality in Long-term Care. OECD health policy studies, OECD publishing; 2013. p. 53-92.

4. Gerritsen DL, Steverink N, Ooms ME, de Vet HCW, Ribbe MW. Measurement of overall quality of life in nursing homes through self-report: the role of cognitive impairment. Qual Life Res. 2007;16(6):1029-37.

5. Spector A, Orrell M. Quality of life (QoL) in dementia: a comparison of the perceptions of people with dementia and care staff in residential homes. Alzheimer Dis Assoc Disord. 2006;20(3):160-5.

6. Boulding W, Glickman SW, Manary MP, Schulman KA, Staelin R. Relationship between patient satisfaction with inpatient care and hospital readmission within 30 days. Am J Manag Care. 2011;17(1):41-8.

7. Tsai TC, Orav EJ, Jha AK. Patient satisfaction and quality of surgical care in US hospitals. Ann Surg. 2015;261(1):2-8.

8. Hoe J, Hancock G, Livingston G, Orrell M. Quality of life of people with dementia in residential care homes. Br J Psychiatry. 2006;188(5):460-4.

9. Hoe J, Katona C, Roch B, Livingston G. Use of the QOL-AD for measuring quality of life in people with severe dementia-the LASER-AD study. Age Ageing. 2005;34(2):130-5.

10. Kane RA, Kling KC, Bershadsky B, Kane RL, Giles K, Degenholtz HB, et al. Quality of life measures for nursing home residents. J Gerontol Ser A. 2003; 58(3):M240-8.

11. Thorgrimsen L, Selwood A, Spector A, Royan L, de Madariaga LM, Woods RT, et al. Whose quality of life is it anyway?: the validity and reliability of the quality of life-Alzheimer's disease (QoL-AD) scale. Alzheimer Dis Assoc Disord. 2003;17(4):201-8.

12. Donabedian A. Explorations in quality assessment and monitoring. Volume I, the definition of quality and approaches to its assessment. Ann Arbor, Ml: Health Administration Press; 1980.

13. Donabedian A. Quality assessment and assurance: Unity of purpose. Diversity of Means Inquiry. 1988;25(1):173-92.

14. Backhaus R, Verbeek H, van Rossum E, Capezuti E, Hamers JPH. Nurse staffing impact on quality of care in nursing homes: a systematic review of longitudinal studies. J Am Med Dir Assoc. 2014;15(6):383-93.

15. Baldwin R, Chenoweth L. dela Rama M, Wang AY. Does size matter in aged care facilities? A literature review of the relationship between the number of facility beds and quality. Health Care Manag Rev. 2017;42(4):315-27.

16. Hillmer MP, Wodchis WP, Gill SS, Anderson GM, Rochon P. a. Nursing home profit status and quality of care: is there any evidence of an association? Med Care Res Rev. 2005;62(2):139-66.

17. Williams J, Hadjistavropoulos T, Ghandehari OO, Yao X, Lix L. An evaluation of a person-centred care programme for long-term care facilities. Ageing Soc. 2015 Mar 7;35(03):457-88.

18. Chou S-C, Boldy DP, Lee AH. Factors influencing residents' satisfaction in residential aged care. The Gerontologist. 2003;43(4):459-72.

19. Bishop CE, Weinberg DB, Leutz W, Dossa A, Pfefferle SG, Zincavage RM. Nursing assistants' job commitment: effect of nursing home organizational factors and impact on resident well-being. The Gerontologist. 2008;48(suppl 1):36-45.

20. Lucas JA, Levin CA, Lowe TJ, Robertson B, Akincigil A, Sambamoorthi U, et al. The relationship between organizational factors and resident satisfaction with nursing home care and life. J Aging Soc Policy. 2007;19(2):125-51.
21. Kenkmann A, Price GM, Bolton J, Hooper L. Health, wellbeing and nutritional status of older people living in UK care homes: an exploratory evaluation of changes in food and drink provision. BMC Geriatr. 2010;10.

22. Poey JL, Hermer L, Cornelison L, Kaup ML, Drake P, Stone Rl, et al. Does person-centered care improve residents' satisfaction with nursing home quality? J am med Dir Assoc. 2017 Jul 25;

23. Tse MMY. Therapeutic effects of an indoor gardening programme for older people living in nursing homes. J Clin Nurs. 2010 Apr;19(7-8):949-58.

24. Erlandsson S, Storm P, Stranz A, Szebehely M, Trydegård G-B. Marketising trends in Swedish eldercare: competition, choice and calls for stricter regulation. In: Meagher G, Szebehely M, editors. Marketisation in Nordic eldercare: a research report on legislation, oversight, extent and consequences. Stockholm: Department of Social Work, Stockholm University; 2013. p. 23-83.

25. OECD. A Good Life in Old Age?: Monitoring and Improving Quality in Longterm Care. OECD Publishing; 2013. (OECD Health Policy Studies).

26. Winblad U, Blomqvist $P$, Karlsson A. Do public nursing home care providers deliver higher quality than private providers? Evidence from Sweden. BMC Health Serv Res. 2017;17(1):487.

27. Hjelmar U, Bhatti $Y$, Petersen OH, Rostgaard T, Vrangbæk K. Public/private ownership and quality of care: evidence from Danish nursing homes. Soc Sci Med. 2018;216:41-9.

28. Kajonius PJ, Kazemi A. Structure and process quality as predictors of satisfaction with elderly care. Health Soc Care Community. 2016;24(6): 699-707.

29. SFS 2001:453. Socialtjänstlag. Stockholm: Socialdepartementet;

30. NBHW. Statistik om äldre och personer med funktionsnedsättning efter regiform 2016 [Statistics about elderly people and people with disabilities by ownership type 2016] [Internet]. Stockholm: The National Board of Health and Welfare (NBHW); 2017 [cited 2019 Mar 28]. Available from: https://www.socialstyrelsen.se/publikationer2017/2017-2-13

31. NBHW. Statistik om särskilt boende [Internet]. Stockholm: The National Board of Health and Welfare (NBHW); 2016 [cited 2019 Mar 28]. Available from: https://www.socialstyrelsen.se/publikationer2016/2016-12-5

32. Moberg L. Marketisation of Nordic eldercare - is the model still universal? J Soc Policy. 2017 Jul 21;46(03):603-21.

33. Moberg L, Blomqvist $P$, Winblad U. Professionalized through audit? Soc Policy Adm: Care workers and the new audit regime in Sweden; 2017.

34. NBHW. Så tycker de äldre om äldreomsorgen 2016 [Internet]. Stockholm; 2017 [cited 2019 Mar 28]. Available from: http://www.socialstyrelsen.se/ publikationer2016/2016-10-2

35. NBHW. Enhetsundersökningen om äldreomsorg och kommunal hälso- och sjukvård, 2016 Nationella resultat, guide för användning, beskrivning av datainsamling och indikatorer [Internet]. Stockholm: The National Board of Health and Welfare; 2016 [cited 2019 Mar 28]. Available from: http://www. socialstyrelsen.se/SiteCollectionDocuments/enhetsundersokningenguide-161018.pdf

36. NBHW. Vad tycker de äldre om äldreomsorgen? - en rikstäckande undersökning av äldres uppfattning om kvaliteten i hemtjänst och äldreboenden 2012. Stockholm; 2012.

37. Rådet för främjandet av kommunala analyser (RKA). Kolada [Internet]. Kommun- och landstingsdatabasen. [cited 2017 Jun 26]. Available from: https://www.kolada.se/?._p=index

38. Gustafsson I-B, Öström $\AA$, Johansson J, Mossberg L. The five aspects meal model: a tool for developing meal services in restaurants. J Foodserv. 2006; 17(2):84-93

39. NBHW. Anvisningar om redovisningen av Omvårdnadslyftet 2014 [Internet]. Stockholm: The National Board of Health and Welfare (NBHW); 2014 [cited 2019 Mar 28]. Available from: https://www. socialstyrelsen.se/SiteCollectionDocuments/anvisningar-redovisning-avomvardnadslyftet-2014.pdf

40. Idler EL, Benyamini Y. Self-rated health and mortality: a review of twentyseven community studies. J Health Soc Behav. 1997;38(1):21-37.

41. DeSalvo KB, Bloser N, Reynolds K, He J, Muntner P. Mortality prediction with a single general self-rated health question. J Gen Intern Med. 2006;21(3):267.

42. Bostick JE, Rantz MJ, Flesner MK, Riggs CJ. Systematic review of studies of staffing and quality in nursing homes. J Am Med Dir Assoc. 2006; 7(6):366-76.

43. Bergman MA, Johansson P, Lundberg S, Spagnolo G. Privatization and quality: evidence from elderly care in Sweden. J Health Econ. 2016:49: 109-19. 
44. Pearl J. Causal diagrams for empirical research. Biometrika. 1995 Dec 1;82(4): 669-88.

45. Harrell FEJ. rms: Regression Modeling Strategies. 2018.

46. Gelman A, Hill J. Data analysis using regression and hierarchical/multilevel models. Cambridge: New York, NY; 2007.

47. Bates $D$, Mächler M, Bolker B, Walker S. Fitting linear mixed-effects models using Ime4. J Stat Softw. 2015 Oct;67(1):1-48.

48. Spangler D. Data for: small is beautiful? Explaining resident satisfaction in Swedish nursing home care [internet]. 2019. Available from: https://doi.org/ 10.17632/y69zhgxym3.2

49. Nakagawa S, Schielzeth $\mathrm{H}$. A general and simple method for obtaining R2 from generalized linear mixed-effects models. Methods Ecol Evol. 2013:4(2):133-42.

50. Carter MW, Porell FW. Variations in hospitalization rates among nursing home residents: the role of facility and market attributes. The Gerontologist. 2003;43(2):175-91.

51. Cioltan H, Alshehri S, Howe C, Lee J, Fain M, Eng H, et al. Variation in use of antipsychotic medications in nursing homes in the United States: a systematic review. BMC Geriatr. 2017;17(1):32.

52. Castle NG, Engberg J. Organizational characteristics associated with staff turnover in nursing homes. The Gerontologist. 2006 Feb 1;46(1):62-73.

53. Rantz MJ, Hicks L, Grando V, Petroski GF, Madsen RW, Mehr DR, et al. Nursing home quality, cost, staffing, and staff mix. The Gerontologist. 2004; 44(1):24-38.

54. Cichocki M, Quehenberger V, Zeiler M, Adamcik T, Manousek M, Stamm T, et al. Effectiveness of a low-threshold physical activity intervention in residential aged care--results of a randomized controlled trial. Clin Interv Aging. 2015;10:885-95.

55. Underwood M, Lamb SE, Eldridge S, Sheehan B, Slowther A-M, Spencer A, et al. Exercise for depression in elderly residents of care homes: a clusterrandomised controlled trial. Lancet. 2013;382(9886):41-9.

56. Mathey M-FAM, Vanneste VGG, De Graaf C, De Groot LC, Van Staveren WA. Health effect of improved meal ambiance in a Dutch nursing home: a 1year intervention study. Prev Med. 2001;32:416-23.

57. Liu W, Galik E, Boltz M, Nahm E-S, Resnick B. Optimizing eating performance for older adults with dementia living in long-term care: a systematic review. Worldviews Evid-Based Nurs. 2015;12(4):228-35.

58. Castle NG. Nursing home caregiver staffing levels and quality of care: a literature review. J Appl Gerontol. 2008;27(4):375-405.

59. Castle NG, Anderson RA. Caregiver staffing in nursing homes and their influence on quality of care. Med Care. 2011;49(6):545-52.

60. Hyer K, Thomas KS, Branch LG, Harman JS, Johnson CE, Weech-Maldonado $R$. The influence of nurse staffing levels on quality of Care in Nursing Homes. The Gerontologist. 2011;51(5):610-6.

61. Shin JH, Hyun TK. Nurse staffing and quality of Care of Nursing Home Residents in Korea. J Nurs Scholarsh. 2015:47(6):555-64.

62. NBHW. Bilaga 4: Fördjupad bortfallsanalys. In: Vad tycker de äldre om äldreomsorgen? - en rikstäckande undersökning av äldres uppfattning om kvaliteten i hemtjänst och äldreboenden 2012. Stockholm: NBHW; 2012. p. 67-69.

63. Wicherts JM, Veldkamp CLS, Augusteijn HEM, Bakker M, van Aert RCM, van Assen MALM. Degrees of freedom in planning, running, analyzing, and reporting psychological studies: a checklist to avoid p-hacking. Front Psychol. 2016;7:1832

64. Mazor KM, Clauser BE, Field T, Yood RA, Gurwitz JH. A demonstration of the impact of response bias on the results of patient satisfaction surveys. Health Serv Res. 2002;37(5):1403-17.

65. Sitzia J, Wood N. Response rate in patient satisfaction research: an analysis of 210 published studies. Int J Qual Health Care. 1998:10(4):311-7.

\section{Publisher's Note}

Springer Nature remains neutral with regard to jurisdictional claims in published maps and institutional affiliations.

Ready to submit your research? Choose BMC and benefit from:

- fast, convenient online submission

- thorough peer review by experienced researchers in your field

- rapid publication on acceptance

- support for research data, including large and complex data types

- gold Open Access which fosters wider collaboration and increased citations

- maximum visibility for your research: over $100 \mathrm{M}$ website views per year

At $\mathrm{BMC}$, research is always in progress.

Learn more biomedcentral.com/submissions 